\title{
CUTTING ENVIRONMENT IMPACT ON THE AluminiUm Alloy MaChining (DFA)
}

\author{
Eva Buranská \& Ivan Buranský
}
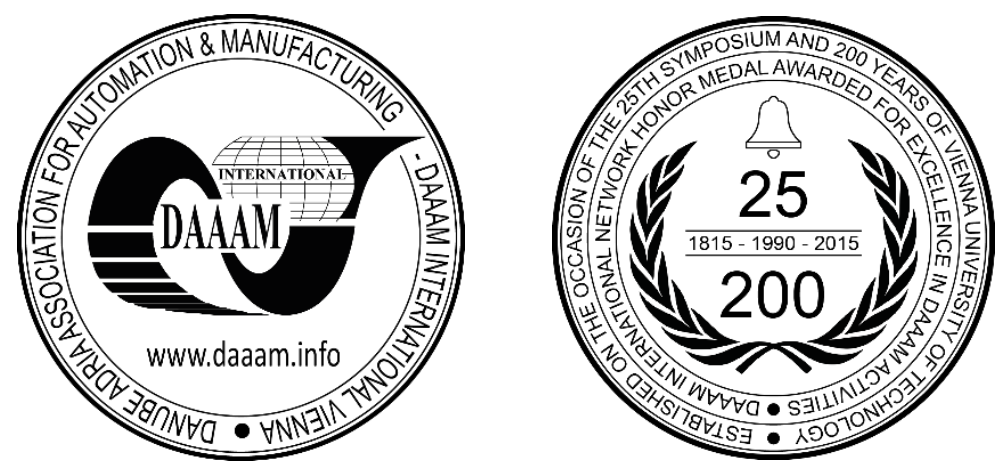

This Publication has to be referred as: Buranska, E[va] \& Buransky, I[van] (2018). Cutting Environment Impact on the Aluminium Alloy Machining (DFA), Proceedings of the 29th DAAAM International Symposium, pp.1158-1163, B. Katalinic (Ed.), Published by DAAAM International, ISBN 978-3-902734-20-4, ISSN 1726-9679, Vienna, Austria DOI: $10.2507 / 29$ th.daaam.proceedings.166

\begin{abstract}
During the drilling process of the aluminium alloy, certain specifications are different from milling and turning. The major differences: 1) a variable cutting speed along the main cutting edge, 2) more difficult chip evacuation, 3) poor access of liquids into the cutting area. One of the problems is to select a suitable cutting environment for drilling the aluminium alloy to ensure the required quality of the bore (mainly roughness and cylindricality). Dry drilling of aluminium alloys (without using cutting fluids) is an environmentally friendly machining process but also an extremely difficult task due to the tendency of aluminium to adhere to the drills made from conventional materials such as high-speed steel, therefore three cutting environments (namely two different emulsions and compressed air) were used this experiment. The paper is focused on the experiment where the effects of the cutting environment and feed of machining on the bores roughness and cylindricity are evaluated. The article demonstrates multicriterial optimization of input factors (cutting environment, feed) for two defined target functions roughness and cylindricity). The measured values were subjected to mathematical - statistical analysis Desirability Function Analysis (DFA). Based on the experiment and studies on this issue combinations of input factors have been identified that have achieved minimum target function values. The results show that the most appropriate combination of the following input factors has been demonstrated: compressed air and feed setting at the lowest level, ie $0.2 \mathrm{~mm}$.
\end{abstract}

Keywords: cutting environment; feed; DFA; drilling; aluminium alloy

\section{Introduction}

Drilling is one of the most useful metal cutting processes and is used in various applications, such as aerospace, electronics, and automotive. In traditional drilling methods, the thrust force, torque, tolerance, and tribology (surface roughness) are related to the cutting condition and tool geometry [1]. Drilling is a very demanding operation because it has certain specifications which differ from milling and turning. The major difference include a variable cutting speed along the main cutting edge, more difficult chip evacuation and poor access of fluids to the cutting area [2].

The dry drilling of aluminium alloys (without using cutting fluids) is an environmentally friendly machining process but also an exceedingly difficult task due to aluminium's tendency to adhere to the drills made of conventional materials such as the high-speed steel [3]. 
Cutting fluids have been used extensively in deep hole machining operations to achieve the following results: 1. to force the chips back out of the deep hole as it is being drilled or bored; 2 . to cool the cutting zone; and 3. to reduce friction and wear [4], [5]. The importance of cutting environment for metals machining continues to grow and has a significant impact on improving the quality of the surface of the workpiece, tool life and reduce energy consumption [6].

However, current environmental and health concerns, require manufacturers to reduce the volume of their waste streams [7]. The dry machining process (i.e., machining without the use of metal removal fluids) satisfies the aforementioned circumstances for steel and other ferrous materials [8], [9], but the dry machining of aluminium and especially the dry drilling of cast Al-Si alloys proved to be difficult due to adhesion of aluminium to the drill.

Therefore, the choice of cooling and cutting materials is an important factor. There is no unanimous opinion, which cutting material is advisable to choose. The most commonly used materials are carbides and diamonds. The adhesive effect is reducing by coating of drills. Our experimental procedure includes drilling and subsequent measurement of roughness and cylindricity by changing cutting environment and feed. The surface quality is one of the most specified customer requirements and surface roughness is the major indicator workpiece surface quality. Surface roughness is mainly the result of various controllable or uncontrollable process parameters, and it is more difficult to achieve and monitor than physical dimensions. A considerable number of studies have examined the effects of cutting speed, feed, depth of cut, nose radius and other factors on the surface roughness [10].

\section{Materials and methods}

Our experiment was performed in the Centre of Excellence of 5 - axis machining at Faculty of Materials Science and Technology in Trnava. A computer numerical control (CNC) milling machine centre DMU 85 monoBLOCK was used. Cutting tool as shows Figure 1: twist drill with $12 \mathrm{~mm}$ of diameter (marking - DH452120-1 produced by YG company) was used. Tool has universal application for bore drilling.

Tool was designed with possibility of internal lubrication. It means that selected cutting environments was fed into the cutting area due the tool. Three new drills were used for machining operations. Parameters of the tool shows Table 1. Table 2 shows chemical composition of workpiece material and Table 3 shows machining parameters.

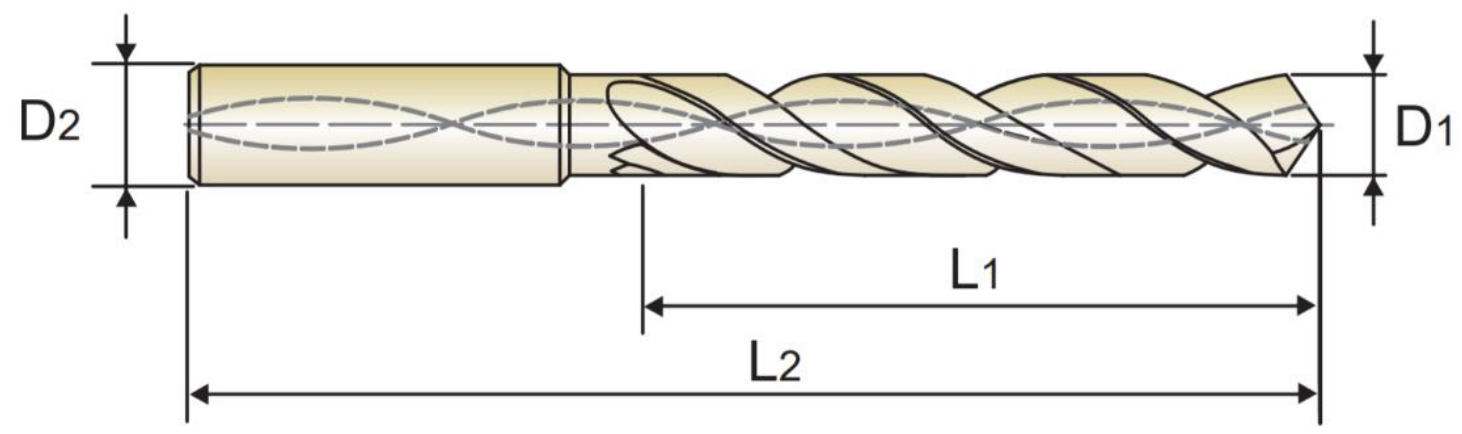

Fig. 1. Twist drill DH452120-1 [7]

\begin{tabular}{cccccc}
\hline $\begin{array}{c}\text { D1 } \\
(\mathbf{m m})\end{array}$ & $\begin{array}{c}\text { D2 } \\
(\mathbf{m m})\end{array}$ & $\begin{array}{c}\text { L1 } \\
(\mathbf{m m})\end{array}$ & $\begin{array}{c}\text { L2 } \\
(\mathbf{m m})\end{array}$ & $\begin{array}{c}\text { Cutting } \\
\text { material }\end{array}$ & Coating \\
\hline 12 & 12 & 71 & 118 & $\begin{array}{c}\text { cemented } \\
\text { carbide }\end{array}$ & TiAlN \\
\hline
\end{tabular}

Table 1. Cutting tool parameters

\begin{tabular}{ccccccccc}
\hline Alloy & Al & Zn & Cu & Fe & Mg & Si & Mn & Ti \\
\hline \% Weight & base & 0,2 & 0,1 & 0,5 & 0,7 & 0,7 & 0,4 & 0,05 \\
\hline
\end{tabular}

Table 2. Chemical composition of workpiece material

\begin{tabular}{cc}
\hline Parameters & Value \\
\hline Cutting speed & $173 \mathrm{~m} / \mathrm{min}$ \\
\hline Feed 1 & $0,2 \mathrm{~mm}$ \\
\hline Feed 2 & $0,3 \mathrm{~mm}$ \\
\hline Feed 3 & $0,4 \mathrm{~mm}$ \\
\hline
\end{tabular}

Table 3. Machining parameters 
For our experiment was selected three types of cutting environment:

1. Emulsion $\boldsymbol{A}$ - performance semi-synthetic water-miscible machining liquid without boron, amines, chlorine and substances which release formaldehyde destined for machining of aluminium alloys (5\% emulsion).

2. Emulsion B - synthetic pH neutral coolant designed especially for demanding machining of aluminium and other alloys (manufacturer recommends a minimum, rate amounts to $6 \%$ concentration for all operations, which ensures reliable protection of metal surfaces against corrosion).

3. Compressed air $\boldsymbol{C}$ - with a pressure of 6,5 $\mathrm{MPa}$.

The bore surface roughness of AlMgSil alloy (ENAW 6082) was measured by the Surtronic 3+ Taylor-Hobson surface roughness tester in three different positions as shows Figure 2. The individually arithmetical mean was done for all the measured values for each hole to get one roughness value, resp. arithmetical mean deviation of the profile for one bole. The bore cylindricity was measured by coordinate measurement machine Prismo 10. For the measurement and evaluation of measured values was used CALYPSO software. For the evaluation of cylindricity 1041 points were scanned. There was used the same procedure as with roughness values.

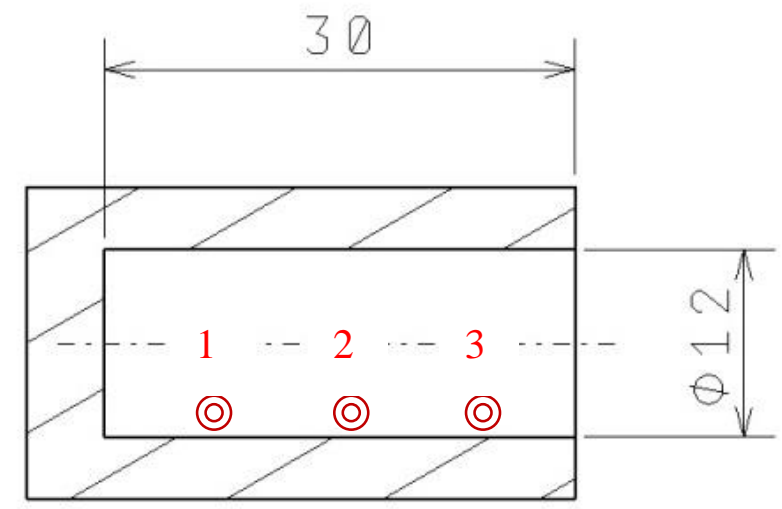

Fig. 2. Three position for measuring hole surface roughness

To obtain higher accuracy, a full factorial DOE for two factors in three levels has been used [11], [12].

\section{Result and Discussion}

One of the ways how to evaluate and analyse the results of the experiment, with respect to the multi-criteria optimization is to use methods of Desirability Function Analysis = DFA. The optimization method consists in defining of the non-dimensional value called suitability coefficient $(\mathrm{dG})$, while its margin expresses the interval $\langle 0 ; 1\rangle$.

Since the aim is to minimize the observed optimization criteria, which are in this case presented by the roughness and cylindricity, the index calculation method for determining the suitability criterion is determined by "The smaller-thebest".

The individual partial indices (among the measured values, resp. responses (y), separately for the case of roughness and then separately for cylindricity) was calculated according to the formula - the smallest measured response has attributed suitability index equal to one and to the largest measured response is attributed suitability index zero. Other responses were then converted according to the formula in the last column of Table 4.

\begin{tabular}{lccc}
\hline Suitability index & 1 & 0 & $y-y_{\max }$ \\
\cline { 1 - 3 } Condition & $y \leq y_{\min }$ & $y \geq y_{\max }$ & $\frac{y}{y_{\min }-y_{\max }}$ \\
\hline
\end{tabular}

Table 4. Formulas for calculating of the suitability sub-indices

The next step was to determined complex suitability indices (dG) (1), which was calculated from the obtained suitability sub-indices according to the relation [13], [14]:

$$
d_{G}=\left(d_{1}^{w 1} \cdot d_{2}^{w 2} \ldots d_{n}^{w n}\right)^{w}
$$

where $d_{G}$ is complex suitability index,

$\mathrm{d}_{1,2}-$ suitability sub-indices,

$\mathrm{w}$ - importance of the factor;

$w=w 1+w 2+\cdots+w n$

Importance of the factors (2) was in this case given as 0.5 , so $\mathrm{w} 1=\mathrm{w} 2=0.5$. 


\begin{tabular}{lccc}
\hline \multirow{2}{*}{$\begin{array}{l}\text { Number of } \\
\text { experiments }\end{array}$} & \multicolumn{2}{c}{ Suitability sub-indices } & $\begin{array}{c}\text { Complex suitability } \\
\text { index }\end{array}$ \\
\cline { 2 - 4 } & dGi (cylindricity) & dGi (Ra) & dG \\
\hline 1 & 0,388991 & 0,763243 & 0,544880 \\
\hline 2 & 0,910092 & 0,635676 & 0,760607 \\
\hline 3 & 0,939450 & 0,429730 & 0,635381 \\
\hline 4 & 0 & 0 & 0 \\
\hline 5 & 0,974312 & 0,219459 & 0,462409 \\
\hline 6 & 1 & 0,089730 & 0,299549 \\
\hline 7 & 0,911927 & 1 & 0,954948 \\
\hline 8 & 0,812844 & 0,878919 & 0,845236 \\
\hline 9 & 0,798165 & 0,671351 & 0,732017 \\
\hline
\end{tabular}

Table 5. Suitability sub-indices and complex indices

The graphs of the mean values of suitability indices are illustrated in the Figure 3 and Figure 4. It represents mean values of suitability indices separately for each of the input factors. These graphs deal with the specifying of the most advantageous value of the input factor in the drilling process, when considering the observed target function. When evaluating the significance of the effect on the target function it can be argued that the greater value of mean level of suitability index is more appropriate level of input factors.

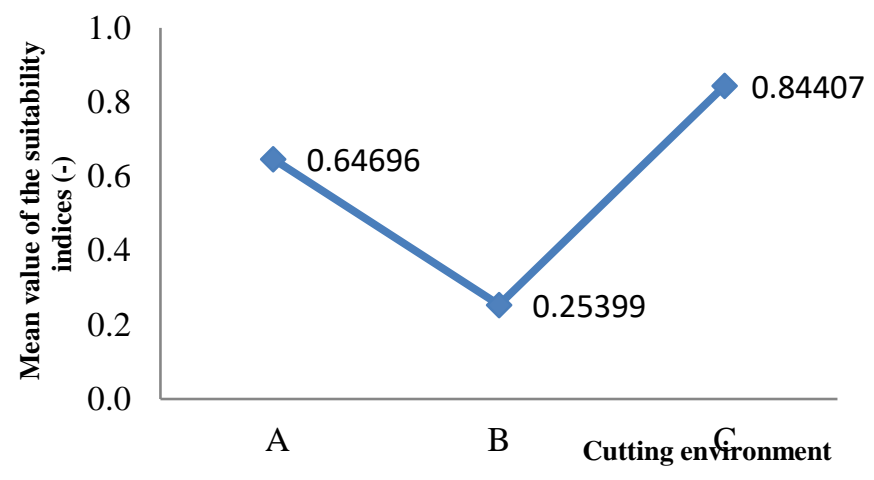

Fig. 3. Graph of the mean suitability indices values for the cutting environment

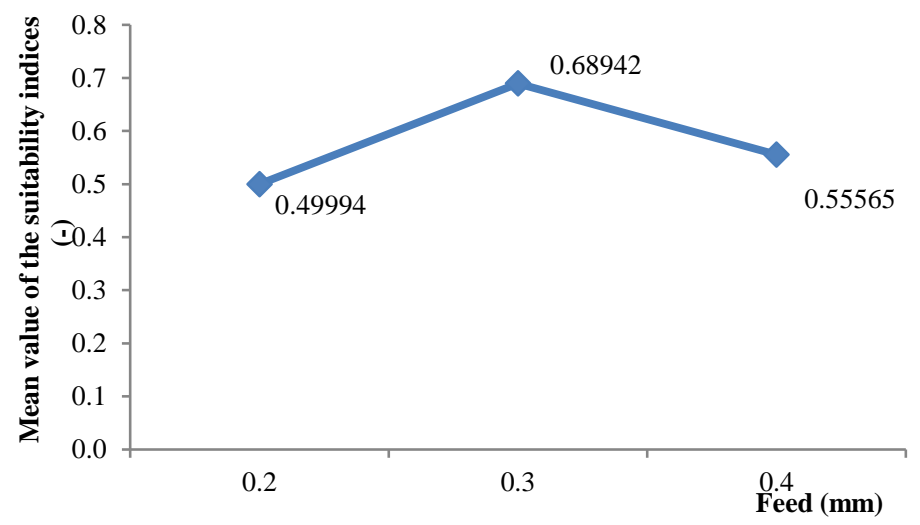

Fig. 4. Graph of the mean suitability indices values for the feed

Figure 4 and Figure 5 show individual effect of the observed factors with respect to the target functions. It is necessary to continue by the calculation of the mean values of the complex suitability indices to obtain the most advantageous level of each parameter. The highest value is the best (Table 6).

These values suggest that in terms of the observed problems the best is the use of the compressed air - C (from the cutting environments used in this experiment). If the feed is evaluated - the best is the use of the medium setting level of this parameter - ie $0.3 \mathrm{~mm}$. 


\begin{tabular}{|c|c|c|c|c|c|}
\hline & \multicolumn{3}{|c|}{ Mean value of the suitability indices } & \multirow[t]{2}{*}{$\mid$ Min - Max $\mid$} & \multirow[t]{2}{*}{ Number } \\
\hline & -1 & $\mathbf{0}$ & 1 & & \\
\hline $\begin{array}{l}\text { Cutting } \\
\text { environment }\end{array}$ & 0,646956 & 0,253986 & 0,844067 & 0,590081 & 1 \\
\hline Feed & 0,499943 & 0,689417 & 0,555649 & 0,189474 & 2 \\
\hline
\end{tabular}

Table 6. Mean values of the suitability indices

For more complex evaluation, it is necessary to focus and consider the interaction between them. For this reason, graphs of mutual interactions were constructed (Figure 6). As a baseline values for constructing of those graphs were used complex suitability indices.

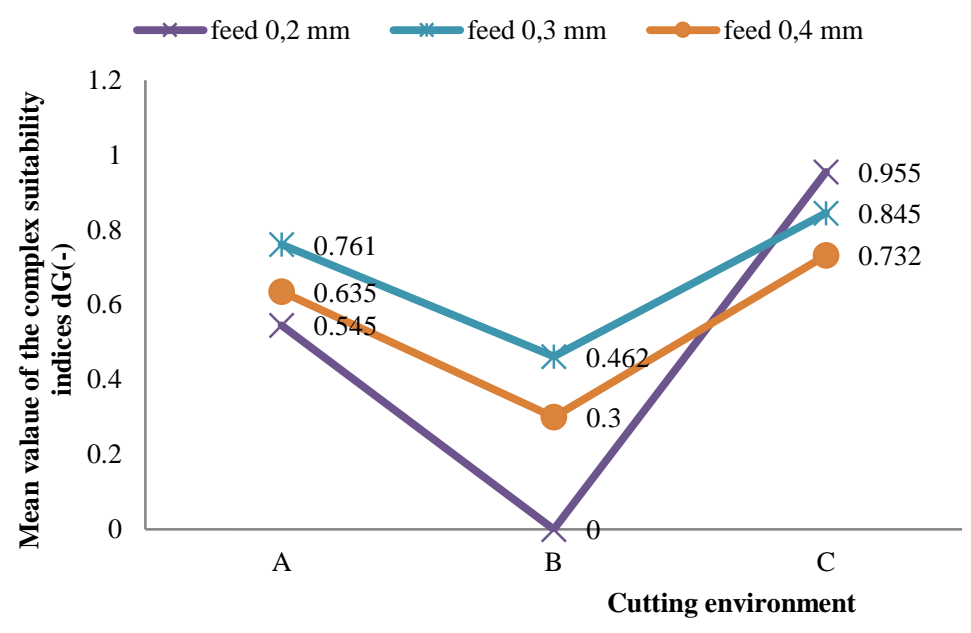

Fig. 5. Graph of the mutual interactions for cutting environment and feed

Figure 6 clearly indicated the best possible combination of input factors. In this case, it is a combination of compressed air and feed on the lowest level, ie $0.2 \mathrm{~mm}$. Graph of the mutual interactions for cutting environment and feed shows the importance to evaluate the process in several ways and identify the mutual interactions between individual input factors, because it does not create distorted results, but rather creates a comprehensive view on discussed problem.

\section{Conclusion}

The aim of the paper was to evaluate the influence of cutting environment and feed of machining on the bores roughness and cylindricity. The multicriteria otptimization of input factors (cutting environment, feed) following two defined functions (roughness and cylindricity) was demonstrated. To obtain the optimal combination of the input factors, DFA methods were used to analyse and evaluate the measured values. Minimal roughness and cylindricity values of the drilled bores appear to be the best combination. The conducted experiment aiming at evaluating rated factors both individually and in their mutual interactions confirmed the importance to examine experiments from several perspectives.

The achieved results confirmed the importance to examine experiments from several aspects. Interactions between various input factors must be considered. Based on our findings the most appropriate combination of the following input factors was proved: a compressed air and feed set at the lowest level, ie $0.2 \mathrm{~mm}$.

In the future research, authors are going to focus on investigation of the cutting environment effects on the cutting edge microgeometry during the machining the difficult materials such as Inconel super-alloy and stainless steel. Authors are also going to determine the influence of edge preparation on the tool life of cemented carbide drilling cutters and cemented carbide milling cutters.

\section{Acknowledgments}

The article was written with the support of the Project of VEGA grant agency of the Ministry of Education, Science, Research and Sport of the Slovak Republic and Slovak Academy of Sciences, no. 1/0097/17: "The research of novel method for cutting edge preparation to increase the tool performance in machining of difficult-to-machine materials", and APVV Project of Slovak Research and development Agency of the Ministry of Education, Science, Research and Sport of the Slovak Republic, no. APVV-16-0057: "Research into the Unique Method for Treatment of Cutting Edge Microgeometry by Plasma Discharges in Electrolyte to Increase the Tool Life of Cutting Tools in Machining of Difficultto-Machine Materials." 


\section{References}

[1] Ghasemi, A. H.; Khorasani, A. M. \& Gibson I. (2018). Investigation on the effect of a pre-center drill hole and tool material on thrust force, surface roughness, and cylindricity in the drilling of Al7075, Materials (Basel), vol. 11, no. 1

[2] Dańa, M.; Zetek, M. \& Schorník,V. (2015). Effect of cutting edge geometry on cutting tool life when drilling inconel 718, Ann. DAAAM Proc. Int. DAAAM Symp., vol. 2015-Janua, no. 2016, pp. 709-714

[3] Bhowmick, S. \& Alpas, A. T. (2008). Minimum quantity lubrication drilling of aluminium-silicon alloys in water using diamond-like carbon coated drills, Int. J. Mach. Tools Manuf., vol. 48, no. 12-13, pp. 1429-1443

[4] Yu, D. G., (2017). Deep hole drill with positive taper and principle for elimination of drill deviation using cutting fluid, Int. J. Adv. Manuf. Technol., vol. 89, no. 9-12, pp. 3195-3206

[5] Kong, L.; Li, Y.; Lv, Y. \& Wang, Q. (2013). Numerical investigation on dynamic characteristics of drilling shaft in deep hole drilling influenced by minimal quantity lubrication, Nonlinear Dyn., vol. 74, no. 4, pp. 943-955.

[6] Králik, M.; Bachratý, M.; Pokusová, M., \& Durakbasa, N. M. (2017). Measuring of friction factor of cutting environment, Ann. DAAAM Proc. Int. DAAAM Symp., pp. 118-123

[7] Weinert, K.; Inasaki, I.; Sutherland, J. W. \& Wakabayashi, T. (2004). Dry Machining and Minimum Quantity Lubrication, CIRP Ann. - Manuf. Technol., vol. 53, no. 2, pp. 511-537

[8] Konca, E.; Cheng,Y. T. ; Weiner, A. M.; Dasch, J. M.; Erdemir,A. \& Alpas, A. T. (2005). Transfer of 319 Al alloy to titanium diboride and titanium nitride based (TiAlN, TiCN, TiN) coatings: Effects of sliding speed, temperature and environment, Surf. Coatings Technol., vol. 200, no. 7, pp. 2260-2270

[9] Klocke, F. \& Eisenblätter, G. (1998). Dry cutting - State of research, VDI Berichte, vol. 46, no. 1399, pp. 159-188

[10] Zhujani, F.; Qehaja, N.; Abdullahu, F. \& Bruqi, M. (2016). Mathematical Modelling of Surface Roughness for Evaluating the Effects of Cutting Parameters in Drilling Process, Ann. DAAAM Proc. Int. DAAAM Symp., pp. 0195-0202

[11] Chen, H.; Chang, S. \& Tang, C. (2017). Application of the Taguchi Method for Optimizing the Process Parameters of Producing Lightweight Aggregates by Incorporating Tile Grinding Sludge with Reservoir Sediments . Materials, vol.10, no. 11, p. 16

[12] Gaaz,T. S.; Sulong, A. B.; Kadhum, A. A. H. \& Nassir, M. H. (2016). Optimizing Injection Molding Parameters of Different Halloysites Type-Reinforced Thermoplastic, Materials, vol. 9, no. 11, p. 19

[13] Neddermeijer H. G., Oortmarssen G. J. ,Piersma N., (2000). A Framework for Response Surface Methodology for Simulation Optimization, Winter Simul. Conf., no. 1996, pp. 129-136

[14] Deng, C. S. \& Chin, J. H. (2005). Hole roundness in deep-hole drilling as analysed by Taguchi methods, Int. J. Adv. Manuf. Technol., vol. 25, no. 5-6, pp. 420-426 